\title{
The Effect of Amifostine, a Cytoprotective Agent, on Paraquat Toxicity in Mice
}

\author{
Brandon K. Wills, DO, MSa,b, Steven E. Aks, DOa,c, Gerry E. Maloney, DOa, James W. Rhee, MDa, \\ Rhonda Brand, PhDd, Marin Sekosan, MDe
}

\author{
aToxikon Consortium, Chicago, IL \\ bDepartment of Emergency Medicine, Madigan Army Medical Center, Tacoma, WA \\ cDepartment of Emergency Medicine, Cook County Hospital, Chicago, IL \\ eDivision of Emergency Medicine, Evanston Northwestern Healthcare and Department of Internal Medicine, Northwestern \\ University, Chicago, IL \\ fDepartment of Pathology, Cook County Hospital, Chicago, IL
}

\begin{abstract}
Background: Paraquat (PQ) is a highly poisonous herbicide with a variety of toxic effects, most notably pulmonary fibrosis. In alveolar epithelial cells, it is converted to a PQ radical and subsequently generates other reactive species resulting in lipid peroxidation and cell destruction. Amifostine is a thiophosphate prodrug approved by the FDA for the prevention of toxicities associated with cisplatin and therapeutic radiation. When amifostine is converted to an active metabolite (WR-1065), it functions as an oxygen and DNA radical scavenger that has been shown to protect against lipoperoxidation. The aim of this study was to determine whether amifostine improves survival or lung injury resulting from PQ toxicity.

Methods: Swiss mice ( $\mathrm{n}=23$ per group) were given an approximate $\mathrm{LD}_{75}$ dose of PQ intraperitoneal (60 mg/kg). Thirty minutes prior to PQ injection, group 1 was pretreated with $200 \mathrm{mg} / \mathrm{kg}$ of amifostine subcutaneously (s.c.). Subsequent doses of amifostine at $75 \mathrm{mg} / \mathrm{kg}$ were administered 4 hours after PQ injection, and injections continued every 8 hours for a total of 6 doses (cumulative dose: $575 \mathrm{mg} / \mathrm{kg}$ ). Four hours after PQ injection, group 2 received $200 \mathrm{mg} / \mathrm{kg}$ of amifostine subcutaneously. Subsequent doses of amifostine at $75 \mathrm{mg} / \mathrm{kg}$ were administered every 8 hours (cumulative dose: $575 \mathrm{mg} / \mathrm{kg}$ ). Four hours after PQ injection, group 3 received $100 \mathrm{mg} / \mathrm{kg}$ of amifostine subcutaneously. Subsequent doses of amifostine at $30 \mathrm{mg} / \mathrm{kg}$ were administered every 8 hours (cumulative dose: 250 $\mathrm{mg} / \mathrm{kg}$ ). Group 4 received equivolume injections of sterile $0.9 \%$ saline s.c. at the same time intervals. We removed lungs from all mice for histologic analysis and injury scoring.

Results: The number of surviving mice in groups 1, 2, 3, and 4 were 17, 18, 17, and 17 respectively. The Kaplan-Meier with log rank analysis showed no differences in survival. Lung injury scores did not differ between treatment groups and the control group for either dead or surviving mice.
\end{abstract}

Conclusion: Amifostine does not appear to improve survival or lung injury due to PQ toxicity at the doses administered.

Keywords: amifostine, paraquat, poisoning, cytoprotective agent, antidote

Acknowledgements: The opinion and assertions contained herein are the views of the author and are not to be construed as official or as reflecting the views of the United States Department of Defense.

Notes: This study was funded by the American College of Medical Toxicology, Ortho-McNeil Research Award for Medical Toxicology Fellows-In-Training; awarded June, 2004. An abstract of this data was presented at the North American Congress of Clinical Toxicology annual meeting, Orlando, FL, September 2005.

Corresponding Author: Brandon Wills, DO, MS, Department of Emergency Medicine, Madigan Army Medical Center, MCHJ-EM, Tacoma, WA 98431. Email: bkwills@gmail.com 


\section{INTRODUCTION}

Paraquat (1,1'-dimethyl-4,4'-bipyridium dichloride, PQ) is a highly toxic contact herbicide that has a variety of toxic effects, most notably pulmonary fibrosis. PQ is concentrated in type II pneumocytes by an active process and passively diffuses into type I pneumocytes and other cells where it is converted to a paraquat radical $\left(\mathrm{PQ}+^{\bullet}\right)$ by oxidizing $\mathrm{NADPH}[1]$. The paraquat radical reacts with oxygen which regenerates paraquat $\left(\mathrm{PQ}^{2+}\right)$ and forms a superoxide radical. Superoxide radicals generate other reactive species such as hydrogen peroxide and hydroxyl radicals. These reactive species cause lipid peroxidation, protein, and DNA degradation which lead to cell destruction. It is controversial whether DNA damage versus lipoperoxidation plays a greater role in paraquat-induced cell damage $[2,3]$.

Although extensive treatment options have been investigated, no universally successful modality has been identified. Treatment with a variety of antioxidants has largely yielded disappointing results. Anti-inflammatory regimens such as glucocorticoids and cyclophosphamide show the greatest promise in reducing lung inflammation, improving oxygen saturation, and decreasing mortality rate in moderate to severely poisoned patients [4-6].

Amifostine is a thiophosphate prodrug that is converted to its active metabolite (WR-1065) by alkaline phosphatase. Amifostine is approved by the FDA for the prevention of toxicities associated with cisplatin and therapeutic radiation. Amifostine's unique cytoprotective effects have been extensively investigated by cancer treatment researchers, and only recently have its effects been studied as a potential antidote in a toxicologic model $[7,8]$. WR1065 is an oxygen and DNA radical scavenger; it interferes with crosslinking of DNA, participates in DNA repair, and induces cellular hypoxia $[9,10]$. Amifostine mostly acts against hydroxyl radicals and-to a lesser extent-O2- ions. It has been shown to protect against lipoperoxidation [11].

\section{OBJECTIVES}

Currently, no universally effective treatment or antidote is available for significant paraquat exposures, and so the aim of this study was to determine whether amifostine improves survival or lung injury in potentially lethal paraquat exposures. The oxidative cascade resulting from paraquat intoxication might be amenable to the unique cytoprotective effects of amifostine, making it an attractive agent to investigate as a potential treatment for paraquat exposures. In addition, amifostine is already used in clinical medicine and is readily available.

\section{METHODS}

\section{Animals}

We obtained committee approval for institutional animal care and use. Male Swiss mice (20-30 g) were used. Animals were housed 5 per cage with a 12-hour light/dark cycle and received temperature/humidity-controlled conditions. Food and water were provided ad libitum throughout the study. Following a seven-day acclimation period, animals were entered into the study.

\section{Phase I: Determination of Paraquat Dose-response Survival Curve}

Due to variability of paraquat lethality in previous reports, we established a $\mathrm{LD}_{75}$ for paraquat in our laboratory [12-14]. The $\mathrm{LD}_{75}$ was chosen to allow for a smaller required sample size needed to detect survival improvement and to prevent supralethal dosing. Paraquat dichloride (Sigma, St. Louis) was suspended in sterile $0.9 \%$ saline and injected intraperitoneally (i.p). Four groups of 11 mice were given i.p injections of paraquat at the following doses: $30 \mathrm{mg} / \mathrm{kg}, 50 \mathrm{mg} / \mathrm{kg}, 70 \mathrm{mg} / \mathrm{kg}$, and 100 $\mathrm{mg} / \mathrm{kg}$. We monitored the mice for up to two weeks at which time survival was assumed.

\section{Phase II: Primary Toxicity Study}

There were 4 groups, and each group contained 23 mice. All animals received a single $\mathrm{LD}_{75}(60 \mathrm{mg} / \mathrm{kg})$ dose of paraquat intraperitoneally. Sterile, lyophilized amifostine contained in 500mg vials (MedImmune Oncology, Inc., West Conshohocken, PA) was reconstituted with sterile $0.9 \%$ saline and subcutaneously delivered (s.c.). Thirty minutes prior to paraquat injection, group 1 was pretreated with $200 \mathrm{mg} / \mathrm{kg}$ s.c. of amifostine. Subsequent injections of amifostine at $75 \mathrm{mg} / \mathrm{kg}$ were administered 4 hours after paraquat injection, and injections continued every 8 hours for a total of 6 doses (cumulative dose: $575 \mathrm{mg} / \mathrm{kg}$ ). Four hours after paraquat injection, group 2 received amifostine at $200 \mathrm{mg} / \mathrm{kg}$ subcutaneously. Subsequent injections of $75 \mathrm{mg} / \mathrm{kg}$ were administered every 8 hours for a total of 6 doses (cumulative dose: 575 $\mathrm{mg} / \mathrm{kg}$ ). Four hours after paraquat injection, group 3 received amifostine $(100 \mathrm{mg} / \mathrm{kg})$ subcutaneously. Subsequent injections of amifostine at $30 \mathrm{mg} / \mathrm{kg}$ were administered every 8 hours for a total of 6 doses (cumulative dose: $250 \mathrm{mg} / \mathrm{kg}$ ). Group 4 served as the control group and received equivolume s.c. injections of sterile $0.9 \%$ saline at the same time intervals as groups 1,2 , and 3 .

Following injections, we monitored animals daily and recorded time of death. Animals were monitored for up to 14 days at which time survival was assumed and animals were euthanized.

\section{Histopathology}

We determined histological changes associated with paraquat intoxication and treatment with amifostine. After death or euthanasia, all mice underwent pneumonectomy. Lungs were placed in $10 \%$ NB formalin, embedded in paraffin, and stained with hematoxylin/eosin and trichrome. We used two groups of histologic control mice ( $\mathrm{n}=5$ per group); one control group only received normal saline injections, and the other control group received amifostine at a cumulative dose of $575 \mathrm{mg} / \mathrm{kg}$ intraperitoneally. A board certified pathologist examined lung sections of mice from the dose-response study (phase I) to develop a scoring 
system for paraquat injury. Injury pattern was scored as none $=0$, mild $=1$, moderate $=2$, and severe $=3$. Markers for injury included interstitial necrosis, alveolar edema, fibrosis, and acute inflammation as described previously $[15,16]$. For the experimental phase, the pathologist was blinded to treatment allocation.

\section{Statistics}

We performed a power analysis and determined sample size: 11 per group for phase I and 23 per group for phase II at a power of 0.8 and $\alpha=0.05$. This was based on an estimated $\Delta / \sigma$ of 1.5 for phase I and 1.0 for phase II. Survival data was entered into a database program and exported to SPSS for analysis (SPSS 10.0.5, 1999). KaplanMeier survival curves with log-rank analysis were calculated using percent survival over time. Differences in histopathology scores were determined using ordinal logistic regression.

\section{RESULTS}

\section{Phase I: Determination of Paraquat Dose-response Survival Curve}

Survival for PQ doses of 30, 50, 70, and $100 \mathrm{mg} / \mathrm{kg}$ was 100, 27, 18 , and $0 \%$ respectively (Figure 1 ). The estimated $\mathrm{LD}_{75}$ for paraquat was calculated to be $60 \mathrm{mg} / \mathrm{kg}$.

\section{Phase II: Primary Toxicity Study}

The number of surviving mice in groups 1, 2, 3, and 4 were 17 (74\%), 18 (78\%), 17 (74\%), and 17 (74\%) respectively (Figure 2). There were no statistically significant differences in survival using Kaplan-Meier with log rank analysis.

\section{Histopathology}

Ordinal logistic regression of lung injury scores revealed survival status had a significant effect on injury score $(p<0.0001)$. Injury scores did not differ between treatment groups and the control group for either dead $(\mathrm{p}=0.49)$ or surviving $(\mathrm{p}=0.58)$ mice (Table 1). Figures 3-6 show photomicrograph examples of grades $0,1,2$, and 3 lung injury respectively.

\section{DISCUSSION}

Significant PQ ingestions in humans (> $40 \mathrm{mg} / \mathrm{kg}$ ) usually result in death within hours to days [17]. Patients with moderate ingestions typically succumb within 2-23 days from severe pulmonary fibrosis [18]. Because of the severe toxicity of $P Q$, there is great need to identify an effective antidote.

Amifostine effectively treats the toxicity of cisplatin and radiation. As a free radical scavenger and inhibitor of lipid peroxidiation, it has theoretical appeal as an antidote for PQ. Following

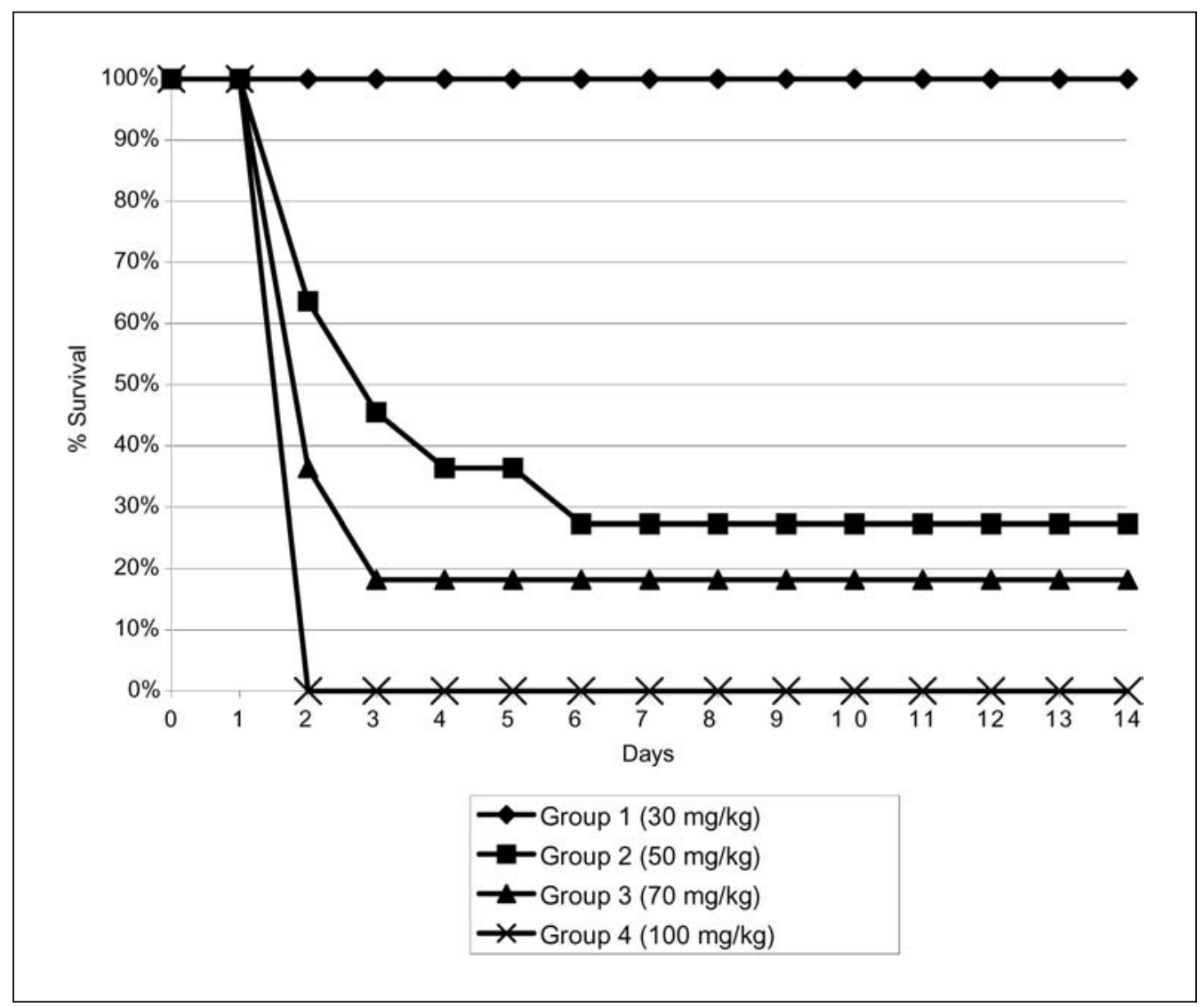

Figure 1. Phase I, Paraquat dose-response. 


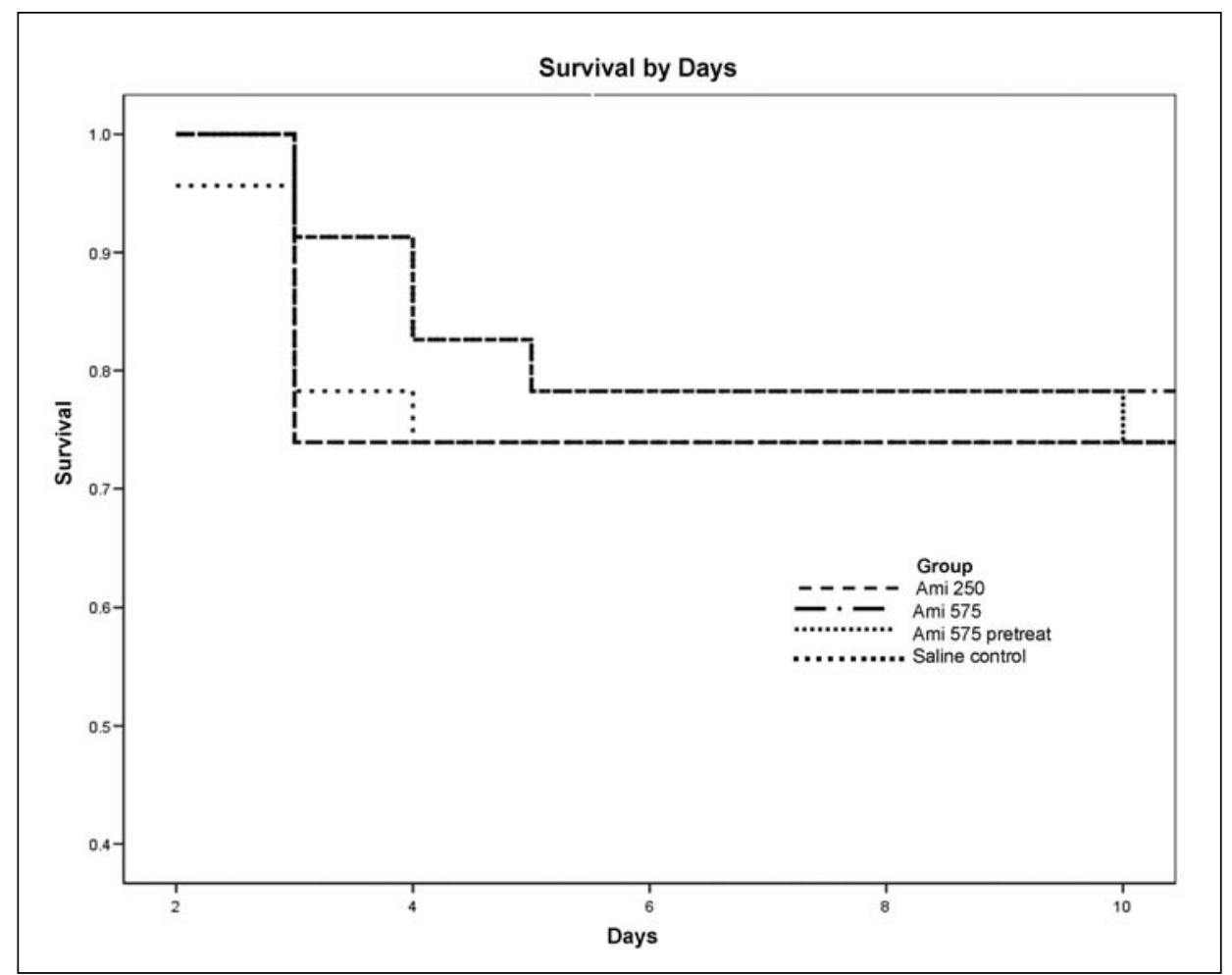

Figure 2. Kaplan-Meier survival curve by number of days following PQ injection.

intravenous or subcutaneous administration, amifostine rapidly distributes to most tissues, including lung; however, there is minimal penetration into brain tissue [19]. Its volume of distribution varies between 6.4-8.4 liters, and plasma clearance is 2.17 liters/minute [10]. Amifostine rapidly clears from plasma with an elimination half-life of 0.88 to 8.8 minutes $[9,10,20]$.
Approximately $2-6 \%$ of amifostine and its metabolites are excreted renally $[9,20]$. Subcutaneous administration results in $50-80 \%$ of the area under the concentration-time curve compared to intravenous injection, and exhibits cytoprotective effects for up to 8 hours [9]. Side effects of amifostine administration include: hypotension, emesis, and mild hypocalcemia

Table 1: Percent of Mice in Each Group Receiving a Particular Injury Score

\begin{tabular}{|c|c|c|c|c|c|}
\hline & Normal (0) & Mild (1) & Moderate (2) & Severe (3) & \% TOTAL \\
\hline \multicolumn{6}{|l|}{ Group 1} \\
\hline Survived & 18 & 71 & 6 & 6 & 100 \\
\hline Died & 0 & 33 & 17 & 50 & 100 \\
\hline \multicolumn{6}{|l|}{ Group 2} \\
\hline Survived & 35 & 41 & 24 & 0 & 100 \\
\hline Died & 0 & 20 & 40 & 40 & 100 \\
\hline \multicolumn{6}{|l|}{ Group 3} \\
\hline Survived & 41 & 53 & 6 & 0 & 100 \\
\hline Died & 0 & 0 & 17 & 83 & 100 \\
\hline \multicolumn{6}{|l|}{ Group 4} \\
\hline \multicolumn{6}{|l|}{ Control } \\
\hline Survived & 35 & 53 & 12 & 0 & 100 \\
\hline Died & 0 & 17 & 17 & 67 & 100 \\
\hline Saline Histo Control & 25 & 75 & 0 & 0 & 100 \\
\hline Ami Histo Control & 0 & 100 & 0 & 0 & 100 \\
\hline
\end{tabular}




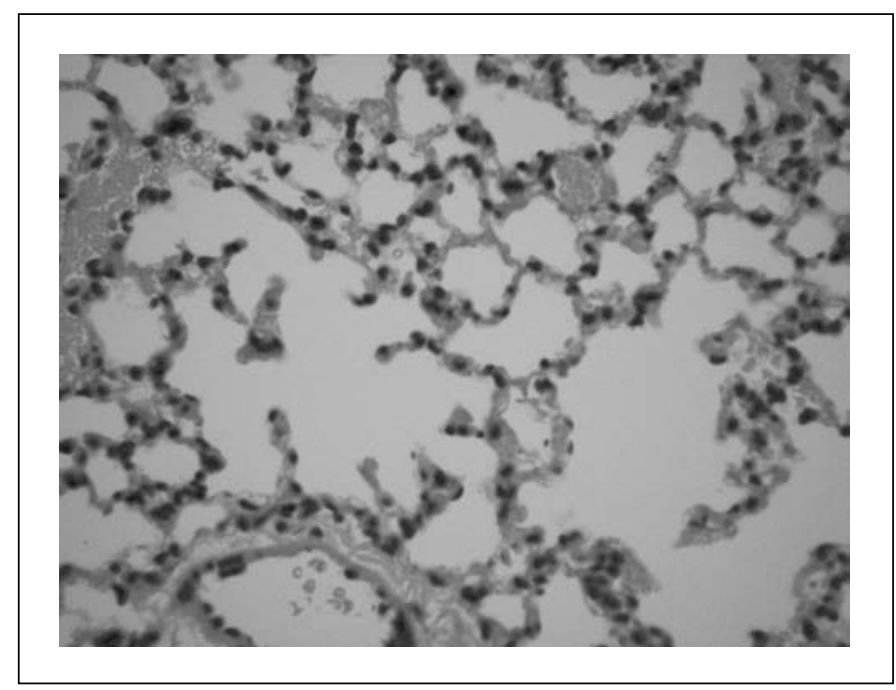

Figure 3. Grade 0 lung injury, normal lung ( $H$ and $E, 40 x)$.

[10]. Hypotension is generally not observed with subcutaneous administration [9].

Optimal dosing of amifostine for a toxicologic model is unknown. Administration of amifostine in human oncology trials frequently employs a single pre-treatment dose of approximately $200-300 \mathrm{mg} / \mathrm{m}^{2}$ for radiation therapy and $740-910 \mathrm{mg} / \mathrm{m}^{2}$ for chemotherapy. This is nearly equivalent to $5-7 \mathrm{mg} / \mathrm{kg}$ and $18-22 \mathrm{mg} / \mathrm{kg}$ respectively. Dosing in animal studies are comparatively larger and typically range from $150-500 \mathrm{mg} / \mathrm{kg}$. Minimal data exist regarding the use of multiple doses of amifostine. A study by Rojas et al. employed multiple doses of amifostine and fractionated radiation in mice. They reported a $\mathrm{LD}_{50}$ of 1000 $\mathrm{mg} / \mathrm{kg}$ for a single injection or a cumulative dose of $4250 \mathrm{mg} / \mathrm{kg}$ divided into 10 injections over 11 days [21]. In a prior study, our lab similarly found evidence of cumulative toxicity and early deaths with a cumulative dose of $1600 \mathrm{mg} / \mathrm{kg}$ in mice poisoned

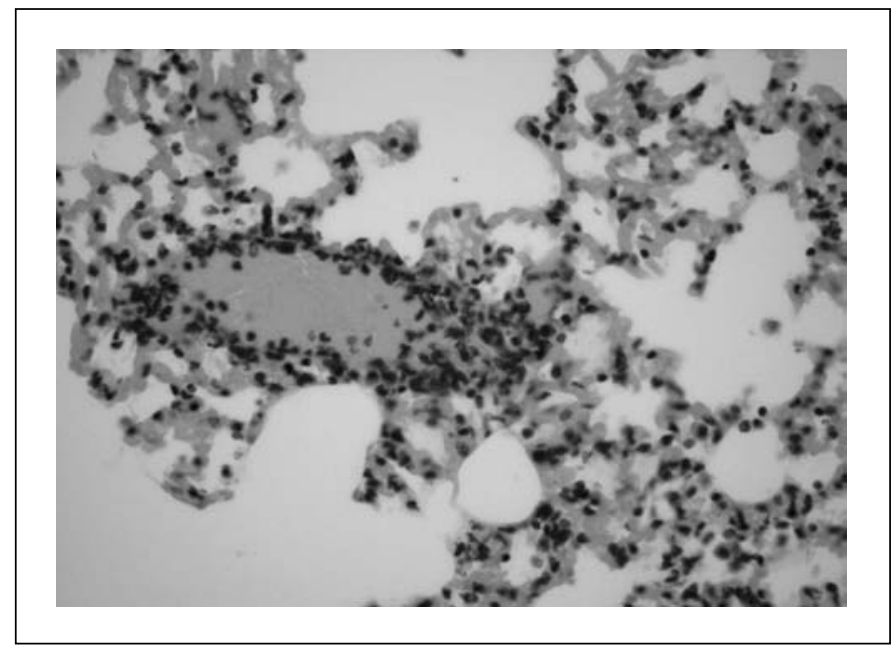

Figure 5. Grade 2 lung injury, moderate perivascular infiltrate $(H$ and $E, 40 x$ ).

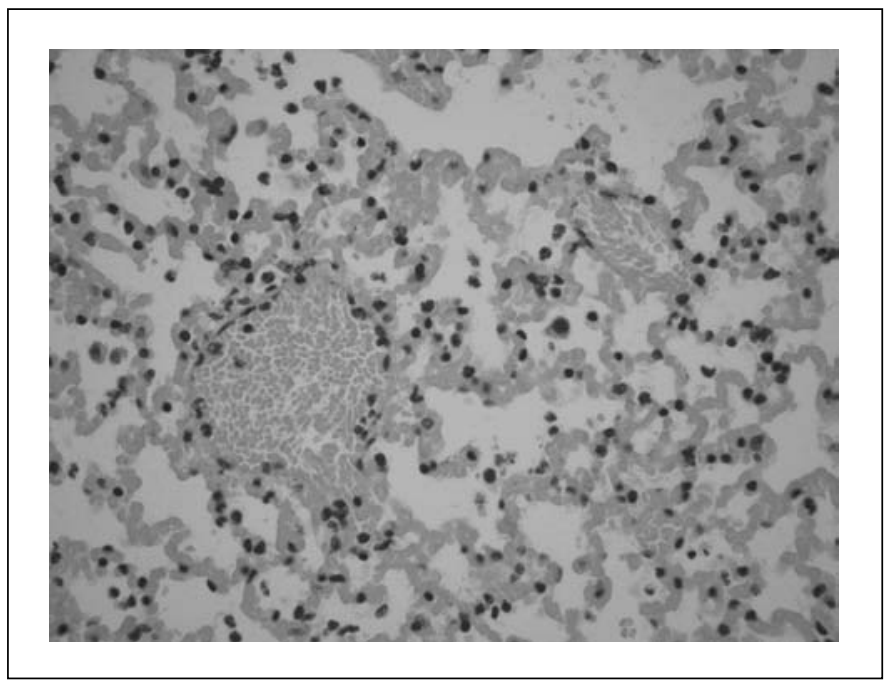

Figure 4. Grade 1 lung injury, mild perivascular infiltrate $(H$ and $E, 40 x)$.

with $\alpha$-amanitin; however, control mice not poisoned with $\alpha$ amanitin tolerated this dose [8]. We chose more moderate subcutaneous doses of amifostine because of its pharmacokinetic profile and our aim to provide sustained cytoprotection during the acute injury phase without causing inherent toxicity.

In our investigation there was no survival benefit or attenuation of lung injury in paraquat-poisoned mice treated with amifostine. Several possibilities for this observation exist. Optimal therapeutic dosing of amifostine in an overdose model is unknown. Given the cumulative toxicity of amifostine, our doses were chosen in an attempt to provide maximal efficacy without causing inherent toxicity. Amifostine should have some efficacy against hydroxyl and superoxide radicals; however, it would not be expected to inactivate either the native paraquat or paraquat radical. Since $\mathrm{PQ}$ is regenerated with each redox cycle, the dosing required to maintain pace might be unrealistic and be toxic in and of itself.

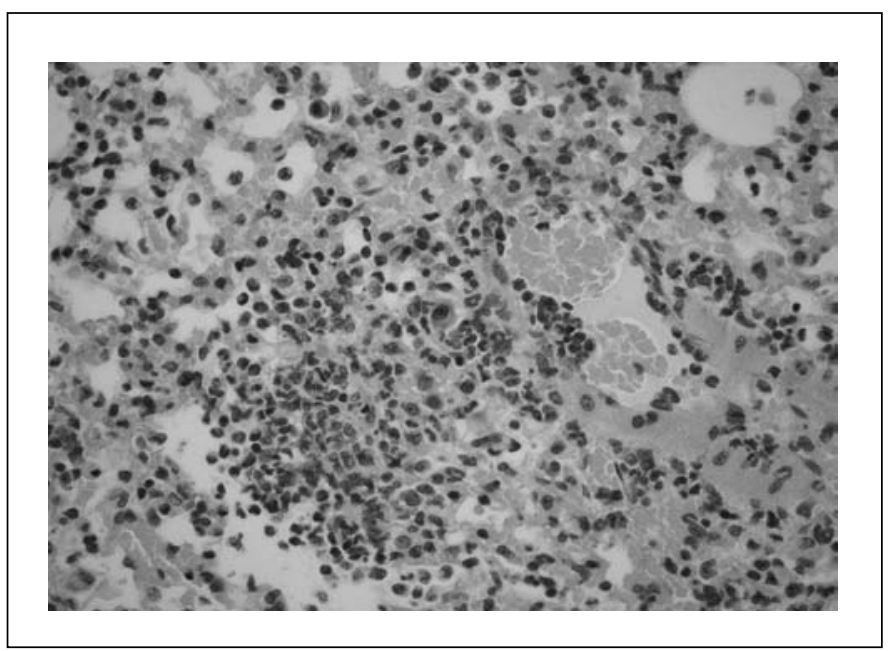

Figure 6. Grade 3 lung injury, perivascular and interstitial infiltrates ( $H$ and $E, 40 x)$. 
Another limitation of this study was that survival in the control group was $74 \%$ despite receiving a $\mathrm{LD}_{75}$ dose of paraquat. Techniques for calculating, diluting, and administering paraquat doses were identical between phase I and II. Mice used for phase II arrived from a different lot and were $5 \mathrm{~g}$ lighter on average. However, with weight-based dosing, this cannot fully explain our observation. Not achieving 75\% mortality in the control group left the study underpowered to detect more subtle improvements in survival. Trends toward improvement in either survival or lung injury score are unlikely to represent a therapeutic benefit; however, further study with different PQ and amifostine doses might provide additional insight into any therapeutic benefit of amifostine in PQ poisoning.

\section{CONCLUSION}

Amifostine does not appear to improve survival or lung injury due to PQ toxicity at the doses administered.

The authors have no potential conflicts of interest to report.

\section{REFERENCES}

1. Forman HJ, Aldrich TK, Posner MA, Fisher AB. Differential paraquat uptake and redox kinetics of rat granular pneumocytes and alveolar macrophages. J Pharmacol Exp Ther. May

1982;221(2):428-433.

2. Dusinska M, Kovacikova Z, Vallova B, Collins A. Responses of alveolar macrophages and epithelial type II cells to oxidative DNA damage caused by paraquat. Carcinogenesis. May 1998;19(5):809-812.

3. Sorensen M, Loft S. No significant paraquat-induced oxidative DNA damage in rats. Free Radic Res. May

2000;32(5):423-428.

4. Lin JL, Leu ML, Liu YC, Chen GH. A prospective clinical trial of pulse therapy with glucocorticoid and cyclophosphamide in moderate to severe paraquat-poisoned patients. Am J Respir Crit Care Med. Feb 1999;159(2):357-360.

5. Newstead CG. Cyclophosphamide treatment of paraquat poisoning. Thorax. Jul 1996;51(7):659-660.

6. Lin JL, Lin-Tan DT, Chen KH, Huang WH. Repeated pulse of methylprednisolone and cyclophosphamide with continuous dexamethasone therapy for patients with severe paraquat poisoning. Crit Care Med. Feb 2006;34(2):368-373.

7. Vijayaraghavan R, Kumar P, Joshi U, et al. Prophylactic efficacy of amifostine and its analogues against sulphur mustard toxicity. Toxicology. Jun 21 2001;163(2-3):83-91.

8. Wills BK, Haller NA, Peter D, White LJ. Use of amifostine, a novel cytoprotective, in alpha-amanitin poisoning. Clin

Toxicol (Phila). 2005;43(4):261-267.

9. Koukourakis MI. Amifostine in clinical oncology: current use and future applications. Anticancer Drugs. Mar

2002;13(3):181-209.

10. Spencer CM, Goa KL. Amifostine. A review of its pharmacodynamic and pharmacokinetic properties, and therapeutic potential as a radioprotector and cytotoxic chemoprotector. Drugs. Dec 1995;50(6):1001-1031.

11. Marzatico F, Porta C, Moroni M, et al. In vitro antioxidant properties of amifostine (WR-2721, Ethyol). Cancer Chemother Pharmacol. 2000;45(2):172-176.

12. Saenghirunvattana S, Sermswan A, Piratchvej V, Rochanawutanon M, Kaojarern S, Rattananenya T. Effect of lung irradiation on mice following paraquat intoxication. Chest. Mar 1992;101(3):833-835.

13. Yamamoto H. Protection against paraquat-induced toxicity with sulfite or thiosulfate in mice. Toxicology. Mar 30 1993;79(1):37-43.

14. Ali S, Diwakar G, Pawa S. Paraquat induces different pulmonary biochemical responses in Wistar rats and Swiss mice. Chem Biol Interact. Mar 1 2000;125(2):79-91.

15. Cheng WH, Ho YS, Valentine BA, Ross DA, Combs GF, Jr., Lei XG. Cellular glutathione peroxidase is the mediator of body selenium to protect against paraquat lethality in transgenic mice. J Nutr. Jul 1998;128(7):1070-1076.

16. Wegener T, Sandhagen B, Chan KW, Saldeen T. N-acetylcysteine in paraquat toxicity: toxicological and histological evaluation in rats. Ups J Med Sci. 1988;93(1):81-89.

17. Pond SM. Manifestations and management of paraquat poisoning. Med J Aust. Mar 5 1990;152(5):256-259.

18. Bismuth C, Garnier R, Baud FJ, Muszynski J, Keyes C. Paraquat poisoning. An overview of the current status. Drug Saf. Jul-Aug 1990;5(4):243-251.

19. Rasey JS, Grunbaum Z, Krohn KA, Menard TW, Spence AM. Biodistribution of the radioprotective drug 35S-labeled 3amino-2-hydroxypropyl phosphorothioate (WR77913). Radiat Res. Apr 1985;102(1):130-137.

20. Links M, Lewis C. Chemoprotectants: a review of their clinical pharmacology and therapeutic efficacy. Drugs. Mar 1999;57(3):293-308.

21. Rojas A, Stewart FA, Soranson JA, Smith KA, Denekamp J. Fractionation studies with WR-2721: normal tissues and tumour. Radiother Oncol. May 1986;6(1):51-60. 